\title{
IIES
}

\section{THE U-SHAPED RELATIONSHIP BETWEEN VERTICAL INTEGRATION AND COMPETITION: THEORY AND EVIDENCE}

\author{
Philippe Aghion \\ Rachel Griffith \\ Peter Howitt
}




\title{
The U-Shaped Relationship Between Vertical Integration and Competition: Theory and Evidence* $^{*}$
}

\author{
Philippe Aghion† Rachel Griffith $\ddagger$ and Peter Howitt ${ }^{\S}$
}

June 12, 2006

\begin{abstract}
This paper considers how competition can affect aggregate innovative activity through its effects on firms' decision whether or not to vertically integrate. A moderate increase in competition enhances innovation incentives, too much competition discourages innovative effort. These effects generates an inverted- $U$ relationship between competition and innovation and between competition and the incentive to vertically integrate. Preliminary evidence finds that there is a non-linear relationship between competition and the propensity of firms to vertically integrate. These results seem to be more consistent with the Property Right Theory (PRT) of vertical integration than with the Transaction Cost Economics (TCE) approach.
\end{abstract}

\section{Introduction}

In previous work (see Aghion et al (2005)), we pointed to the existence of an inverted-U shaped relationship between competition and innovation. Our explanation for this relationship would emphasize the "composition effect" competition has on the steady-state distribution of technological gaps across industries. The present paper is part of an attempt at analyzing how competition can affect aggregate innovative activity through its effects on firms' organization. Our focus is on firms' decision whether or not to vertically integrate, with the following driving intuition: a moderate increase in product market competition, by improving the outside options of a non-integrated supplier, will enhance her innovation incentives, which in turn may encourage the downstream producer

${ }^{*}$ This essay is in honor of Jean-Michel Grandmont. We thank Pol Antras, Oliver Hart and Elhanan Helpman for useful discussions.

${ }^{\dagger}$ Harvard University

¥University College London and IFS

$\S$ Brown University 
to also innovate more. However, too much competition on the producer's market will end up discouraging the producer's effort in a non-integrated firm, as too much of the innovation surplus will then accrue to the supplier. This again generates an inverted- $U$ relationship between competition and innovation, but which is mirrored by a similar relationship between competition and the incentive to vertically integrate.

Showing the existence of an inverted-U relationship between competition and vertical integration sheds light on the debate between those who believe more in the "Transaction Cost Economics" (TCE) approach to vertical integration, pioneered by Williamson $(1975,1985)$, and those who support the "Property Right Theory" (PRT) approach, developed by Grossman-Hart (1986) and HartMoore (1990). ${ }^{1}$ According to the TCE approach, vertical integration is a way for contracting parties involved in a specific-relationship to limit ex post bargaining inefficiencies due to hold-up, and thereby minimize the loss in ex ante investment that would result from it. This approach thus predicts a positive correlation betwen vertical integration and the degree of relation specificity. According to the PRT approach, the ownership structure will affect not so much the ex post bargaining efficiency but rather the relative bargaining powers of the (two) contracting parties, and therefore their relative ex ante investment incentives. Thus, while vertical integration should enhance both parties' investments positively in the TCE approach, by reducing the extent of ex post inefficiency, in the PRT approach ownership by one party, say the buyer, will enhance the buyer's ex ante incentives at the expense of the seller's ex ante incentives, as it enhances the buyer's bargaining power ex post at the expense of the seller's bargaining power. ${ }^{2}$ Thus the TCE approach predicts that increased competition on the producer's (or supplier's) market, which reduces the overall degree of asset specificity, should therefore reduce the need for vertical integration in order to preserve ex ante investment incentives by either party. On the other hand, as already suggested by our discussion above, and as we show more formally in Section 2 below, the PRT approach predicts a U-shaped relationship between vertical integration and competition on the producer's market. In Section 3 we argue that this U-shaped pattern is supported by the empirical analysis of vertical integration and entry using UK cross-firm panel data.

\footnotetext{
${ }^{1}$ A first attempt at deriving distinguishing testable implications of the two approaches, is by Whinston (2001).

2 An attempt at using cross-industry micro panel data to tell these two theories apart was made in Acemoglu-Aghion-Griffith-Zilibotti (2005). Using technology intensity to measure relationship-specific investments, they look at the relationship between pairs of supplying and producing industries, and show that, as predicted by the PRT approach, (backward) vertical integration - that is, producer ownership - is significantly correlated with the investment incentives of suppliers and producers, as measured by their respective R\&D intensities, but with opposite signs.
} 


\section{Basic framework}

\subsection{Production and ex post bargaining}

We consider an economy composed of individuals with risk-neutral preferences for consumption. A final good is produced with a continuum of intermediate inputs according to:

$$
y=\int_{0}^{1} x_{i}^{\alpha} d i
$$

where $\alpha \in(0,1)$.

In each sector $i$, the incumbent producer produces her intermediate good according to:

$$
x_{i}=f\left(z_{i}, s_{i}\right),
$$

where $z_{i}$ is the input of general good used as capital into the production of intermediate input, and $s_{i}$ is the input of a specialized good, used only in sector $i$, and available in supply equal to one.

The production function for intermediate input satisfies:

$$
f\left(z_{i}, s_{i}\right)=\left\{\begin{array}{c}
z_{i} \text { if } s_{i} \geq 1 \\
0 \text { otherwise }
\end{array} .\right.
$$

Thus the specialized input $s_{i}$ is indispensable to the production of intermediate $\operatorname{good} i$.

Although she enjoys monopoly power, intermediate good producer $i$ faces a competitive fringe of firms that can produce the same intermediate good but at higher unit cost. More precisely, potential imitators can produce according to the technology

$$
f^{m}\left(z_{i}, s_{i}\right)=\left\{\begin{array}{c}
\frac{z_{i}}{a} \text { if } s_{i} \geq 1 \\
0 \text { otherwise }
\end{array},\right.
$$

where $a>1$ measures the degree of product market competition in the intermediate input market, with lower $a$ (that is, closer to 1 ) corresponding to a higher degree of competition.

If the incumbent firm (call him "the entrepreneur") in sector $i$ manages to obtain the services of the specialized input producer (call him "the manager") in that sector, she does not face any effective competition, since potential imitators then do not have access to the specialized input. The incumbent firm can then sell her intermediate good to the final sector at the unconstrained monopoly price, which is equal to the marginal product of the intermediate good in producing the final good,

$$
p_{i}=\alpha x_{i}^{\alpha-1}
$$

if, as we shall assume throughout, the final sector is competitive. Thus, the intermediate producer in sector $i$ will choose $z_{i}$ to maximize joint surplus, namely:

$$
\pi_{i}=\max _{z_{i}}\left\{p_{i} f\left(z_{i}, 1\right)-z_{i}\right\},
$$


where

$$
x_{i}=f\left(z_{i}, 1\right)=z_{i} .
$$

Equivalently therefore, the intermediate producer will choose $x_{i}$ to

$$
\max _{x_{i}}\left\{\alpha x_{i}^{\alpha}-x_{i}\right\}=\pi_{i}
$$

which in turn, by first-order conditions, immediately yields:

$$
\pi_{i}=\frac{1-\alpha}{\alpha} \alpha^{\frac{2}{1-\alpha}}=\pi .
$$

To determine how this surplus is divided between the intermediate entrepreneur and the manager, we need to compute what the manager would obtain if he sold his specialized input to imitators. The answer is that, if the fringe of imitators is competitive, the manager should get the whole surplus $\pi_{i}^{m}$ from selling his input to an imitator. That surplus, in turn, is determined by the same maximization program as above, except that the production function $f$ is replaced by $f^{m}$, namely:

$$
\pi_{i}^{m}=\max _{z_{i}}\left\{p_{i} f^{m}\left(z_{i}, 1\right)-z_{i}\right\}
$$

where now

or equivalently

$$
x_{i}=f^{m}\left(z_{i}, 1\right),
$$

$$
\max _{x_{i}}\left\{\alpha x_{i}^{\alpha}-a x_{i}\right\}
$$

This immediately yields

$$
\pi_{i}^{m}=\frac{\pi}{\chi}
$$

where

$$
\chi=a^{\frac{\alpha}{1-\alpha}}
$$

also measures product market competition.

Now, we can easily determine the outcome of ex post bargaining between the intermediate producer (or entrepreneur) and the specialized input supplier (or manager) in each intermediate sector $i$.

First, if a competitive fringe of imitators shows up, the manager can secure $\pi_{i}^{m}$ by defecting to an imitator. Assuming that the incumbent entrepreneur makes a take-it-or-leave it offer to the manager ex post, she will concede $\pi_{i}^{m}$ to the manager to secure his specialized input, so that the entrepreneur's ex post residual payoff is simply equal to

$$
\pi_{i}-\pi_{i}^{m}=\pi\left(1-\frac{1}{\chi}\right) .
$$

If no competitive fringe shows up, or if the entrepreneur integrates backward with her manager, then we assume that ex post bargaining results in the entrepreneur and the manager splitting the total surplus 50-50, so that the manager and the entrepreneur each get:

$$
\frac{\pi}{2}
$$


Here we implicitly assume that

$$
\chi<2
$$

so that the outside option of the manager moving to the imitator is actually binding.

\subsection{Ex ante investments}

We assume that the incumbent firm in any sector $i$ must invest in R\&D in order to innovate. Innovation, in turn, creates the profit opportunity $\pi$. Let $d(z)$ denote the $\mathrm{R} \& \mathrm{D}$ cost of innovating with probability $z$, and assume that

$$
d(z)=\frac{z^{u_{1}}}{u_{1}}
$$

where $u_{1}>1$.

Once a new technology has been invented by the incumbent producer, the manager must create a suitable input or component for that new technology, and we let $c(e)$ denote the manager's cost of generating such a component with probability e. We let:

$$
c(e)=\frac{e^{u_{2}}}{u_{2}}
$$

where $u_{2}>1$.

\subsection{Timing of events}

At the beginning of a period the incumbent producer in any sector invests in quality-enhancing innovation. If she successfully innovates, then she turns to the specialized input supplier in that sector for him to come up with a component which is adapted to the new technology. Then a competitive fringe of potential imitators on the intermediate market show up with probability $\eta>0$. Whether the fringe shows up or not, if the component is successfully produced, then the entrepreneur and the manager bargain over the surplus. Otherwise they both get zero profits, as the previous technology keeps prevailing in that intermediate sector.

\section{Imitation, competition, and the choice between integration and non-integration}

\subsection{Equilibrium payoff under vertical integration}

Suppose first that the entrepreneur in any sector $i$ chooses to integrate backward with her input supplier. Then, the ex post surplus will be divided 50-50 between the two parties. Then, moving back one step, once a new technology has been 
successfully invented the input supplier or manager will choose his probability $e$ of discovering the complementary component so as to

$$
\max _{e}\left\{e \frac{\pi}{2}-c(e)\right\}
$$

which yields

$$
e^{V I}=\left(\frac{\pi}{2}\right)^{\varepsilon_{2}}
$$

where

$$
\varepsilon_{2}=\frac{1}{u_{2}-1}
$$

measures the marginal efficiency of the manager's effort.

Moving back one further step, anticipating innovation effort $e^{V I}$ by the manager, the entrepreneur will choose her own R\&D intensity $z$ to

$$
\max _{z}\left\{z e^{V I} \frac{\pi}{2}-d(z)\right\}=U^{V I},
$$

which in turn depends upon

$$
\varepsilon_{1}=\frac{1}{u_{1}-1}
$$

which measures the marginal efficiency of the producer's effort.

\subsection{Equilibrium payoff under non-integration}

Now, suppose that the incumbent entrepreneur in sector $i$ chooses not to integrate with her input supplier. Then, we know from the previous section that her residual surplus will be equal to

$$
\pi\left(1-\frac{1}{\chi}\right)
$$

and the manager's residual surplus will be

$$
\frac{\pi}{\chi}
$$

if potential imitators show up, whereas in the absence of imitation both parties obtain

$$
\frac{\pi}{2}
$$

Moving back one step, once a new technology has been successfully invented the manager will choose his probability $e$ of discovering the complementary component so as to

$$
\max _{e}\left\{e \pi\left(\eta \frac{1}{\chi}+(1-\eta) \frac{1}{2}\right)-c(e)\right\}
$$

which yields

$$
e^{N I}=\left(\eta \frac{1}{\chi}+(1-\eta) \frac{1}{2}\right)^{\varepsilon_{2}} \pi^{\varepsilon_{2}}
$$


which is greater than $e^{V I}$ whenever the competitive fringe is binding, that is $\chi<2$.

Note that the case where imitation never occurs (that is, when $\eta=0$ ) is identical to the case under vertical integration, which is not surprising since in either case the manager has no outside option.

Moving back one further step, anticipating innovation effort $e^{N I}$ by the manager, the entrepreneur will choose her own R\&D intensity $z$ to

$$
\max _{z}\left\{z e^{N I}\left(\eta\left(1-\frac{1}{\chi}\right)+(1-\eta) \frac{1}{2}\right) \pi-d(z)\right\}=U^{N I} .
$$

\subsection{Imitation and vertical integration}

Comparing between (3) and (4), we can establish:

Lemma 1 The difference $U^{N I}-U^{V I}$ either always decreases, or always increases, or first increases and then decreases as the probability of imitation $\eta$ increases from zero to one.

Proof. Consider the function

$$
\nu(\eta)=\left(\eta \frac{1}{\chi}+(1-\eta) \frac{1}{2}\right)^{\varepsilon_{2}}\left(\eta\left(1-\frac{1}{\chi}\right)+(1-\eta) \frac{1}{2}\right) .
$$

Once we fully spell out the expressions for (3) and (4), all we need to show is that $\nu$ is either increasing, or decreasing, or inverted-U shaped in $\eta$. To this effect, let us calculate the derivative $\nu^{\prime}(\eta)$. We have:

$$
\nu^{\prime}(\eta)=\left(\frac{1}{\chi}-\frac{1}{2}\right)\left(\eta \frac{1}{\chi}+(1-\eta) \frac{1}{2}\right)^{\varepsilon_{2}-1}\left[\frac{\varepsilon_{2}-1}{2}-\eta\left(\varepsilon_{2}+1\right)\left(\frac{1}{\chi}-\frac{1}{2}\right)\right] .
$$

If $\nu$ was U-shaped, we would have:

$$
\nu^{\prime}(0)<0<\nu^{\prime}(1)
$$

or equivalently

$$
\frac{\varepsilon_{2}-1}{2}<0<\frac{\varepsilon_{2}-1}{2}-\left(\varepsilon_{2}+1\right)\left(\frac{1}{\chi}-\frac{1}{2}\right) .
$$

But this cannot be since

$$
\frac{1}{\chi}>\frac{1}{2}
$$

by assumption. This establishes the lemma.

This lemma in turn immediately implies:

Proposition 2 As the probability of imitation increases from zero to one, either the entrepreneur always chooses vertical integration, or she always chooses non-integration, or she chooses non-integration for $\eta$ sufficiently small, and integration otherwise. The latter case is more likely to occur when competition is high and the marginal efficiency of the manager's effort is also sufficiently high. 
Proof. The proposition results immediately from Lemma 1 together with the fact that investments and the entrepreneur's utility under vertical integration are the same as under non-integration and $\eta=0$. In particular, the entrepreneur will choose vertical integration always when $\nu^{\prime}(\eta)<0$ for all $\eta$, she will choose non integration always when $\nu^{\prime}(\eta)>0$ for all $\eta$, and she will choose non-integration for small values of $\eta$ and integration otherwise when $\nu(\eta)$ is inverted-U shaped. This latter case occurs when $\varepsilon_{2} \nu^{\prime}(\eta)<0$ for all $\eta$ is sufficiently large and $\chi$ is sufficiently close to 1 .

\subsection{Competition and vertical integration}

Let us now fix the imitation (or entry) probability $\eta$ but look at how the optimal choice of governance structure varies with competition as measured by $\chi$. Let

$$
x=\frac{1}{\chi} .
$$

We know that the function $U^{N I}(x)-U^{V I}$ behaves like the $\nu$-function defined in the previous subsection, and therefore, using (5) and taking logarithms, like the function:

$$
\ln \nu(x)=\varepsilon_{2} \ln \left(\eta x+(1-\eta) \frac{1}{2}\right)+\ln \left(\eta(1-x)+(1-\eta) \frac{1}{2}\right) .
$$

Proposition 3 The function $U^{N I}(x)-U^{V I}$ cannot be U-shaped: it is either increasing, or decreasing, or inverted- $U$ shaped.

Proof. By contradiction, suppose that the $U^{N I}(x)-U^{V I}$ curve was Ushaped. The same then would be true of the $\ln \nu(x)$ function, where $x$ varies from $1 / 2$ (minimum competition) to 1 (maximum competition). But then the derivative

$$
\Delta(x)=\frac{d \ln \nu(x)}{d x}
$$

would be negative at $x=1 / 2$ and positive at $x=1$. From (5) we immediately get:

$$
\Delta(x)=\frac{\varepsilon_{2} \eta}{\eta x+(1-\eta) \frac{1}{2}}-\frac{\eta}{\eta(1-x)+(1-\eta) \frac{1}{2}},
$$

which in turn implies that

$$
\Delta(1 / 2)=2\left(\varepsilon_{2}-1\right) \eta .
$$

If the $\ln \nu(x)$ was U-shaped, we would have $\Delta(1 / 2)<0$ or equivalently:

$$
\varepsilon_{2}<1 \text {. }
$$

But then:

$$
\begin{aligned}
\Delta(1) & =\frac{\varepsilon_{2} \eta}{\eta+(1-\eta) \frac{1}{2}}-\frac{\eta}{(1-\eta) \frac{1}{2}} \\
& <\frac{\eta}{\eta+(1-\eta) \frac{1}{2}}-\frac{\eta}{(1-\eta) \frac{1}{2}}<0,
\end{aligned}
$$


which in turn implies that $\ln \nu(x)$ is not U-shaped. This contradiction establishes the proposition.

\section{Empirical evidence}

We are interested in investigating whether the propensity for firms to vertically integrate varies systematically with the extent of competition in the product market, and if so whether it does so in ways that are consistent with the TCE view of vertical integration or the PRT view. Recall that under the former we would expect vertical integration to decline as competition increases. In contrast, Proposition 3 states that under the PRT as competition increases the probability of vertical integration could follow this pattern, but could also increase or initially decrease and then increase.

We look at how the probability of a producer and supplier being vertically integrated varies with several simple measure of competition. We should emphasize that what we are capturing here is a correlation, and not a causal relationship.

\subsection{Data}

We use a large nationally representative data set on all UK manufacturing plants $^{3}$ over a thirteen year period (1980-1992) combined with information from the UK Input-Output Tables. We identify whether each firm in a producing industry is vertical integrated or not with any firm in each potential supplying industry. Plants are identified by their 4-digit industry. The Input-Output Tables indicate the linkages between industries. The Input-Output table contains information on 77 manufacturing industries (supplying and producing). For each industry pair we calculate the proportion of total costs (including intermediate, labour and capital) of producing that good that are made up of that input, and we retain those industry pairs where this is at least $1 \%{ }^{4}$

We use these data at the level of the producing-supplying industry pair for each year. We consider each producing-supplying industry pairs for each firm. We denote the firm as vertically integrated in that industry pair if (a) there is a positive trade flow indicated in the IO Table, and (b) the firm owns at least one plant operating in each industry. We then aggregate to the industry pair level, defining a variable that is the proportion of producing firms in each industry

\footnotetext{
${ }^{3}$ This is the UK Annual Business Inquiry (ABI), also known as the ARD data. See Acemoglu et al (2005) for further details. The ARD contains information on all production activity located in the UK. Location, owership structure, industry and employment is reported on all plants. Single plant firms are identified as those reporting units which represent only one plant and which have no sibling, parent or child plants. Single plants with fewer than 20 employees are dropped from the analysis.

${ }^{4}$ We use the Input-Output table for 1995. Plants in the ARD in these years are classified by their major product according to 4-digit standard industrial classification (SIC code). Inputoutput (IO) tables are reported at the 2/3-digit level. Where more than one reporting unit exists within an IO industry these are aggregated so that there is only one observation per firm in each IO industry. This is available at www.statistics.gov.uk.
} 
pair that also own a plant in the supplying industry. The mean of this variable is just under $15 \%$.

We proxy competition using the entry rate (the number of new firms over the total number of firms), and the entry rate of foreign firms.

\subsection{Results}

We show the correlation between our proxies of competition and the proportion of firms that are vertically integrated. We estimate the probability of being vertically integrated, so Proposition 3 implies this should be a U shaped. The first column of the Table shows the correlation between competition, as measured by the entry rate, and the proportion of producing firms that are vertically integrated with a supplier. The probability of vertical integration is initially declining in competition but then, at higher levels of competition, is increasing. In column (2) we include the entry rate in the supplying industry along with the age and size (measured by employment) of the producing firm and an indicator of whether the producing firm is foreign-owned. Figure 1 shows the pattern of this correlation, normalised to zero at zero entry. At lower levels of entry, as entry increases the probablity of vertical integration declines (in line with both PRT and TCE approaches). This gradually diminishes, and above a certain level the correlation switches. As a robustness check in column (3) we also include the share of inputs (used by producers) that are imported.

In column (4) we use an alternative entry rate, looking just at entry by foreign firms. We might be concerned that entry is a noisy measure of competition. Foreign firms are in general larger and represent a more substantial competitive threat. ${ }^{5}$ Figure 2 plots the relationship between entry and vertical integration implied by these estimates. Here we see that the upward part of the curve dominates - in line with the predictions of the PRT approach but not the TCE approach.

\section{Concluding comments}

In this paper we have provided some preliminary evidence to suggest that there is a non-linear relationship between competition and the propensity of firms to vertically integrate. These results seem to be more consistent with the Property Right Theory (PRT) of vertical integration than with the Transaction Cost Economics (TCE) approach.

\footnotetext{
${ }^{5}$ See Aghion, Blundell, Griffith, Howitt and Prantl (2005).
} 


\section{References}

Aghion, Philippe, Bloom, Nick, Blundell, Richard, Griffith, Rachel, and Peter Howitt (2005), "Competition and Innovation: An Inverted-U RElationship", Quarterly Journal of Economics, Vol. 120, No. 2, pp. 701-728.

Acemoglu, Daron, Aghion, Philippe, Griffith, Rachel and Fabrizio Zilibotti (2004), "Vertical Integration and Technology: Theory and Evidence", IFS Working Papers, W04/34.

Caves, Richard, and Ralph Bradburd (1988), "The Empirical Determinants of Vertical Integration", Journal of Economic Behavior and Organizations, 9, 265279 .

Feenstra, Robert (1998), "Integration of Trade and Disintegration of Production", Journal of Economic Perspective, 12, 31-50.

Grossman, Sandford and Oliver Hart (1986), "The Costs and Benefits of Ownership: A Theory of Vertical and Lateral Integration," Journal of Political Economy, 94, 691-719.

Hart, Oliver and John Moore (1990), "Property Rights and the Nature of the Firm", Journal of Political Economy, 98, 1119-1158.

Joskow, Paul (1987), "Contract Duration and Relationship-Specific Investments: Empirical Evidence from Coal Markets", American Economic Review, 77, 168185.

Joskow, Paul (2003), "Vertical Integration", forthcoming in the Handbook of New Institutional Economics.

Klein, Benjamin (1998), "Vertical Integration As Organized Ownership: the Fisher Body-General Motors Relationship Revisited" Journal of Law, Economics and Organization, 4, 199-213.

Klein, Benjamin, Crawford, Robert, and Armen Alchian (1978), "Vertical Integration, Appropriable Rents, and the Competitive Contracting Process," Journal of Law and Economics, 21, 297-326

Whinston, Michael (2001), "Assessing the Property Rights and TransactionCost Theories of Firm Scope", American Economic Review, Papers and Proceedings, 91, pp 184-188.

Williamson, Oliver (1975), Markets and Hierarchies: Analysis and Antitrust 
Implications, Free Press, New-York.

Williamson, Oliver (1985), The Economic Institutions of Capitalism, Free Press, New-York.. 


\begin{tabular}{|c|c|c|c|c|}
\hline $\begin{array}{l}\text { Dep var: Proportion of firms } \\
\text { that are vertically integrated }\end{array}$ & (1) & (2) & (3) & (4) \\
\hline Producing entry rate & $\begin{array}{l}-0.618 \\
(0.104)\end{array}$ & $\begin{array}{l}-0.149 \\
(0.070)\end{array}$ & $\begin{array}{l}-0.666 \\
(0.101)\end{array}$ & \\
\hline Producing entry rate ${ }^{2}$ & $\begin{array}{c}0.989 \\
(0.223)\end{array}$ & $\begin{array}{c}0.347 \\
(0.177)\end{array}$ & $\begin{array}{c}1.023 \\
(0.210)\end{array}$ & \\
\hline Supplying entry rate & & $\begin{array}{c}0.581 \\
(0.084)\end{array}$ & $\begin{array}{c}0.230 \\
(0.029)\end{array}$ & \\
\hline Supplying entry rate ${ }^{2}$ & & $\begin{array}{l}-1.462 \\
(0.199)\end{array}$ & $\begin{array}{l}-0.106 \\
(0.033)\end{array}$ & \\
\hline Producing foreign entry rate & & & & $\begin{array}{l}-0.606 \\
(0.250)\end{array}$ \\
\hline Producing foreign entry rate ${ }^{2}$ & & & & $\begin{array}{l}11.507 \\
(3.937)\end{array}$ \\
\hline Supplying foreign entry rate & & & & $\begin{array}{c}1.524 \\
(0.352)\end{array}$ \\
\hline Supplying foreign entry rate ${ }^{2}$ & & & & $\begin{array}{l}-50.712 \\
(7.350)\end{array}$ \\
\hline Age & & $\begin{array}{c}0.006 \\
(0.004)\end{array}$ & $\begin{array}{c}0.003 \\
(0.003)\end{array}$ & $\begin{array}{c}0.008 \\
(0.003)\end{array}$ \\
\hline Employment & & $\begin{array}{c}0.012 \\
(0.008)\end{array}$ & $\begin{array}{c}0.01 \\
(0.008)\end{array}$ & $\begin{array}{c}0.012 \\
(0.008)\end{array}$ \\
\hline Foreign-owned & & $\begin{array}{c}0.081 \\
(0.041)\end{array}$ & $\begin{array}{c}0.036 \\
(0.036)\end{array}$ & $\begin{array}{c}0.090 \\
(0.042)\end{array}$ \\
\hline Share of inputs imported & & & $\begin{array}{c}-0.040 \\
(0.016)\end{array}$ & \\
\hline Year effects & yes & yes & yes & yes \\
\hline
\end{tabular}

Notes: Regressions include 15,990 observations at the industry-pair year level over the period 1980-1992. The dependent variable is the proportion of firms in the industry pair that are vertically integrated. Numbers in parentheses are robust standard errors that are clustered at the producing industry level. There are 181 producing industries. 
Figure 1: correlation between entry and vertical integration

calculated using estimates from column (2) of Table

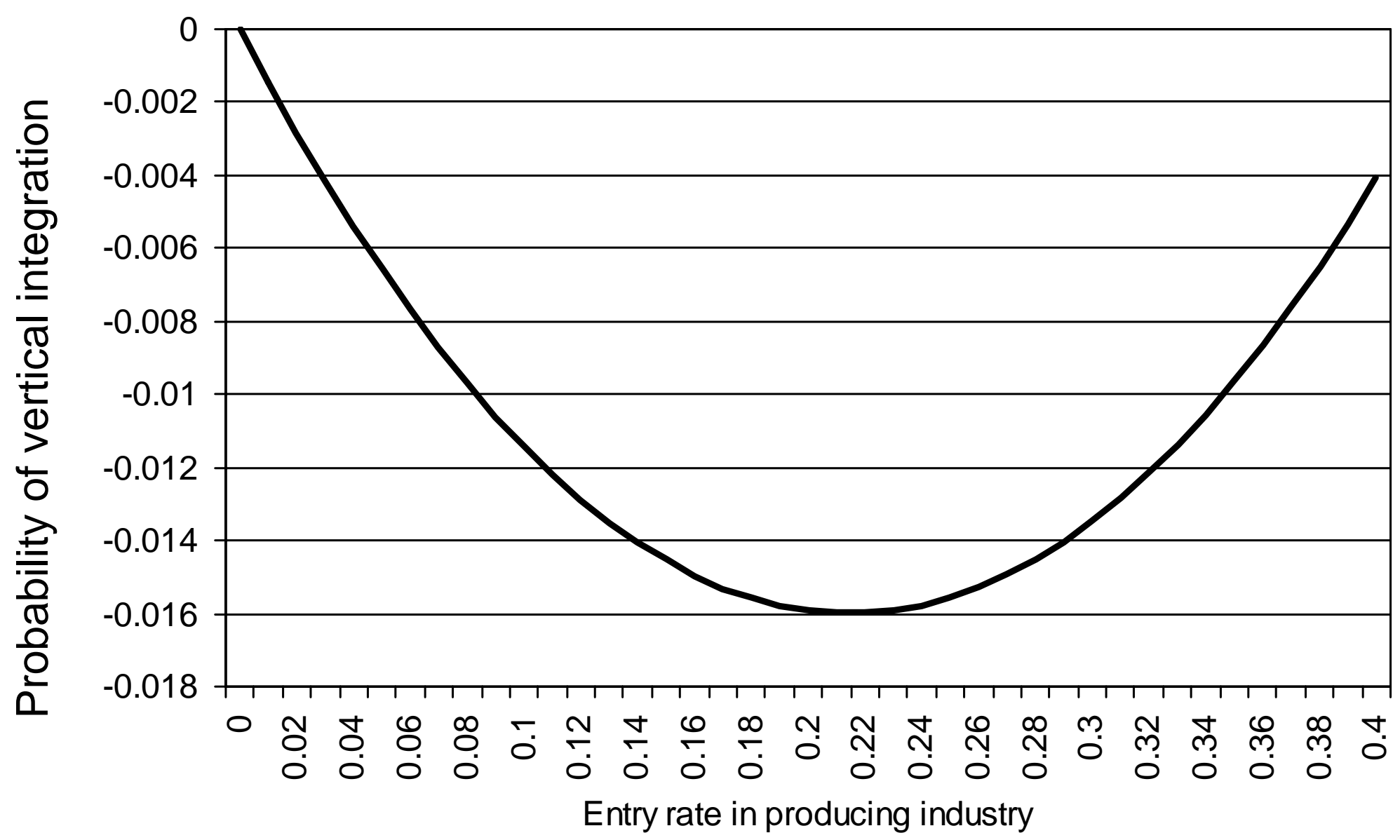


Figure 2: correlation between foreign entry and vertical integration

calculated using estimates from column (4) of Table.

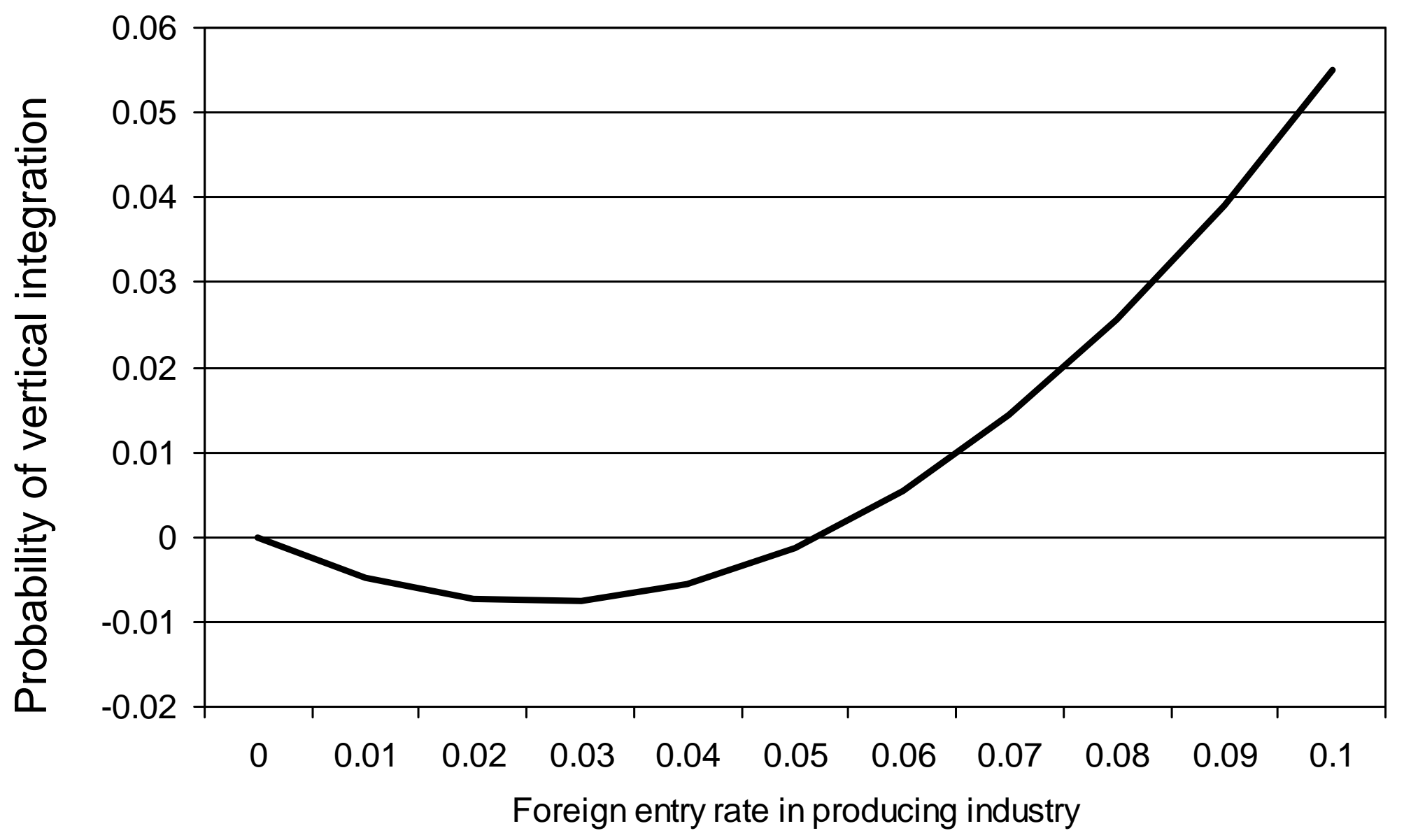

